\title{
Stimmung, Arte Ambiental e corpo político em Hélio Oiticica
}

\author{
Stimmung, Environmental Art \\ and Political Body in Hélio Oiticica
}

\author{
Stimmung, Arte Ambiental \\ y cuerpo político en Hélio Oiticica
}

Luiza B. Amaral ${ }^{*}$

http://dx.doi.org/10.22409/poiesis.1932.37-52

\begin{abstract}
RESUMO: Este breve ensaio tensiona o conceito de Stimmung (atmosfera) de Hans Ulrich Gumbrecht e as leituras de ambiência na Arte Ambiental de Hélio Oiticica. Parte-se do conceito de Stimmung e suas nuances de significados; em seguida, investiga-se como o conceito de arte ambiental se constitui na perspectiva do artista brasileiro, utilizando como fontes dessa investigação suas obras e textos e também escritos de Mário Pedrosa. Analisa-se o Parangolé e os Bólides indicando como a proposta ambiental de Oiticica constrói uma leitura política do corpo atravessada por seus significados sociais e suas afecções.
\end{abstract}

PALAVRAS-CHAVE: Stimmung; Arte Ambiental; corpo político

\footnotetext{
" Luiza B. Amaral é doutoranda em História Social da Cultura na linha de Teoria e História da Arte e da Arquitetura pela PUC-Rio. Email: lubauff@gmail.com
} 
ABSTRACT: This essay relates the concept of Stimmung (atmosphere) by Hans Ulrich Gumbrecht to the readings of ambience in the Environmental Art of Helio Oiticica. Firstly, the concept of Stimmung is introduced, and then we investigate how the concept of environmental art was built by the Brazilian artist. It is used as sources of this investigation his works and texts, besides the writings by Mario Pedrosa. Parangolé and the Bolides are analyzed indicating how the environmental proposal of Oiticica constructs a political reading of the body crossed by social meanings and by the afeccions.

KEYWORDS: Stimmung; Environmental Art; political body

RESUMEN: Este breve ensayo tensiona el concepto de Stimmung (atmósfera) de Hans Ulrich Gumbrecht y las lecturas de ambiente en el Arte Ambiental de Helio Oiticica. Se parte del concepto de Stimmung y sus matices de significados; a continuación, se investiga como el concepto de arte ambiental se constituye en la perspectiva del artista brasileño, utilizando como fuentes de esa investigación sus obras y textos y también escritos de Mário Pedrosa. Se analiza el Parangolé y los Bólides indicando cómo la propuesta ambiental de Oiticica construye una lectura política del cuerpo atravesada por sus significados sociales y sus afecciones.

PALABRAS CLAVE: Stimmung; Arte ambiental; cuerpo politico

Como citar: AMARAL, Luiza B. Stimmung, Arte Ambiental e corpo político em Hélio Oiticica. Poiésis, Niterói, v. 19, n. 32, p. 37-52, jul./dez. 2018.

doi: http://dx.doi.org/10.22409/poiesis.1932.37-52

Poiésis, Niterói, v. 19, n. 32, jul./dez. 2018. 


\section{Stimmung, Arte Ambiental e corpo político em Hélio Oiticica}

\section{Nuances do conceito de Stimmung}

O conceito de Stimmung exige uma estratigrafia; tanto a palavra em alemão quanto a leitura dela como conceito teórico apresentam sobrepostas camadas de sentidos ${ }^{1}$. Partindo da palavra, Stimmung é derivada do radical Stimme ou stimmen que tem sentidos diferentes, a primeira designa voz, tom e voto, enquanto a segunda, verbo stimmen, significa estar de acordo, gerar um sentimento definido e afinar um instrumento musical. A amplitude de significados do radical é um dos indicadores dessa complexidade de traduzir esse termo, já que Stimmung pode ser lido como estado mental, atmosfera, ambiência e afinação. Atualmente, a discussão de Stimmung é revisitada pelo teórico alemão Hans Ulrich Gumbrecht no livro Atmosfera, ambiência, Stimmung: sobre um potencial oculto da literatura (2014). Ao abordar a transposição desse conceito para outras línguas, Gumbrecht destaca a tradução para a língua inglesa, na qual palavras como mood e climate se aproximam do sentido da palavra em alemão². 
A Stimmung está relacionada a um olhar sobre a recepção, sobre o que afeta o receptor na relação com algo externo ou objetivo como uma obra de arte ou a natureza. Gumbrecht recorre ao sentido de afinação, de audição - relacionado à música -, e também à metáfora de clima atmosférico para refletir sobre essa harmonia, sobre esse encontro entre o corpo e o entorno material, o produto/produtor e o receptor que em afinação com essa ambiência tem sua audição e corpo afetado, como sugere a citação a seguir:

Interessa-me muito o componente de sentido que relaciona Stimmung com as notas músicas e com escutar os sons. [...] 0 sentido da audição é uma complexa forma de comportamento que envolve todo o corpo. [...] Cada tom percebido é, claro, uma forma de realidade física (ainda que invisível) que "acontece" aos nossos corpos e que, ao mesmo tempo, os "envolve". Outra dimensão da realidade que acontece aos nossos corpos de modo semelhante é o clima atmosférico. Precisamente por isso, muitas vezes as referências à música e ao tempo atmosférico aparecem na literatura quando os textos tornam presentes - ou começam a refletir sobre - os estados de espírito e as atmosferas. Ser afetado pelo som, pelo clima atmosférico é uma das formas de experiência mais fáceis e menos intrusivas, mas é fisicamente, um encontro [...] muito concreto com nosso ambientefísico. (GUMBRECHT, 2014, p. 13)

A análise de Gumbrecht parte da literatura, mas também caminha por entre a música e as artes visuais tecendo uma análise climática tal como a investigação sobre a energia iconoclasta do surrealismo e, em outro ensaio, sobre a dimensão atmosférica da pintura de Caspar David Friedrich. Essa perspectiva ampliada sobre diferentes tipos de linguagens artísticas como produtoras de atmosferas cabe na medida em que o teórico afirma que qualquer elemento que contenha um texto, seja literal ou imagético, é passível de produzir uma afetação dos estados de espírito.

Sobre os efeitos de ambiência, Gumbrecht analisa as pinturas de Caspar David Friedrich alegando que nelas há uma harmonia entre o observador e o quadro. Partindo de uma leitura kantiana, os quadros de Friedrich encenam o sublime, passam pela desarmonia, pela inadequação entre as faculdades, uma leitura da desproporção entre homem e natureza. Apesar dessa perspectiva kantiana da desarmonia, Gumbrecht indica um outro caminho para compreensão dessas obras, apontando para a relação harmônica existente entre ob-

Poiésis, Niterói, v. 19, n. 32, jul./dez. 2018. 
servador e a obra que é dada a partir da presença da figura humana representada de costas como nas telas Penhascos de giz de Rügen (1818), Mulher diante da aurora (1818) e Viajante sobre um mar de névoa (1818). O observador se depara com um outro observador; trata-se do observador de segunda ordem nomeado por Niklas Luhman que, segundo Gumbrecht, indica uma emergência da observação de segunda ordem. Podemos pensar, a partir dessa análise, que a presença dessa figura humana de costas nas telas atua como mediadora entre o observador (fora do quadro) e o observador (dentro do quadro), e essa harmonia entre ambos produz um efeito de imersão do observador externo nesse ambiente.

A visão de Gumbrecht sobre a experiência da recepção em que o receptor é envolvido em atmosferas de modo afetivo e corporal abre possibilidades para relacionarmos essa leitura às produções artísticas contemporâneas que focam na dimensão relacional (BOURRIAUD, 2009), investigando, a partir delas, o que está para além da obra, como a compreensão dos afetos, da experiência estabelecida entre fruidor, obra e artista. Tal foco indica percepções sobre o que extrapola ao textual como outra forma de se capturar contornos culturais de determinado contexto histórico tal como a análise de Jonathan Flatley (2017) sobre Andy Warhol, baseado em uma composição climática que engloba as obras e a vida do artista.

Flatley capta nas ações do artista, em suas falas e obras, elementos que compõem os contornos de sua teoria estética a partir do conceito de Like. Analisar as ações de Warhol, para o autor, não se trata de fazer uma biografia ou uma análise psicologizante, uma psico-história do artista, mas, ao contrário, observar que essas ações, pelas maneiras de se colocar no mundo, de sentir, de afetar-se são elementos que estruturam o gostar de Warhol. Na montagem desse conceito, Flatley parte do lugar de inadequação ocupado por Warhol: sua origem familiar imigrante e operária, sua atração sexual por homens, o tom de pele extremamente branca e incomum, sua calvície, referenciais sociais, sexuais e estéticos que não pertencem aos padrões socialmente estabelecidos. Esse deslocamento possibilitou a construção de novas formas de afeto e de relação a partir de maneiras de viver não normativas. (FLATLEY, 2017, p. 7) A palavra em inglês like carrega o sentido de 
gostar e de "ser como"; em Warhol essa ambivalência é mantida: like tem sentido de gostar, de sentir atração e de parecer, imitar, categorias que dialogam com a sociedade de massa. O indivíduo, ao se chocar com uma gama de imagens de consumo em outdoors, na televisão e em outras mídias, deve responder a esse estímulo de forma rápida. Neste ponto, o like é uma categoria estética que está ambientada nessa sociedade de mídia massificada que estimula o consumo da imagem, o like como imitar e também como gostar-consumir.

Para Flatley, o mood é o que permite reunir esses contornos afetivos que estão como fragmentos suspensos no contexto sociocultural norte-americano nos anos 1960. Flatley se apoia em uma leitura da estrutura de sentimento ${ }^{3}$ para compor sua análise; em diferentes momentos, ele faz essa menção ao conceito de clima (mood), baseado na leitura de Stimmung feita por Martin Heidegger, que tem uma conotação musical compreendido como sintonização, atmosfera ou meio em que o pensamento, o fazer, o agir e o sentir estão envoltos. Como destaca Flatley, citando Heidegger: "Embora o mood muitas vezes não seja percebido, é apenas através do mood e pelo mood que encontramos o mundo: 'o mood já revelou, em vários casos, o Ser-no-mundo como um todo, e torna possível, antes de tudo, dirigir-se para algo' ". (FLATLEY, 2017, p. 41)

\section{Tensionando ambiências: Arte Ambiental de Hélio Oiticica}

A potência produtora de atmosferas pode ser vista em obras de Oiticica como os Núcleos e os Parangolés, que compõem ambientes de forma diferente: a primeira produz uma atmosfera baseada na espacialização da cor, enquanto a segunda atua na dimensão relacional, no contato com indivíduo que o veste, na harmonia/afinação entre corpo e o material. Essa "arte ambiental", como denomina o crítico Mário Pedrosa no texto Arte Ambiental, Arte Pós-Moderna, Hélio Oiticica (1965), empenha-se e direciona-se à criação de uma ambientação, como expressa no seguinte trecho:

Arte ambiental é como Oiticica chamou sua arte. [...] 0 conjunto perceptivo sensorial domina. Nesse conjunto criou o artista uma "hierarquia de ordens" - Relevos, Núcleos, Bólides (caixas) e capas, estandartes,

Poiésis, Niterói, v. 19, n. 32, jul./dez. 2018. 
tendas (Parangolés) - "todas dirigidas para a criação de um mundo ambiental." (PEDROSA, 2004 [1965], p. 11)

Neste texto, Pedrosa faz uma análise das obras de Oiticica como os Núcleos, os Bólides, os Parangolés, tecendo uma reflexão sobre as dimensões ambientais que as mesmas produzem, de diferentes maneiras ${ }^{4}$.

O Penetrável é descrito como experiência da cor que se materializa no espaço e envolve o sujeito na obra, na experimentação da cor ele a toca, a vê, a respira, interagindo com ela como se a mesma fosse o próprio ambiente que direciona sua experiência e envolve o indivíduo. Ou seja, a cor em escala espacial é a arquitetura da ambiência. Para Pedrosa:

Invadia-se de cor, sentir o contato físico da cor, ponderava a cor, tocava, pisava, respirava a cor. [...] Os Núcleos são estruturas vazadas, placas coloridas de madeira suspensa, traçando um caminho [...]. A cor não está mais trancada, mas no espaço circundante abrasado de um amarelo ou de um laranja violento. São cores-substâncias que se desgarram e tomam 0 ambiente, e se respondem no espaço[...]. 0 ambiente arde, incandescente, a atmosfera é de preciosismo decorativo ao mesmo tempo aristocrático e com algo de plebeu e de perverso. (PEDROSA, 2004 [1965], p. 11)

Em outro momento do texto, Pedrosa expõe que a mudança do olhar de Oiticica sobre a experiência visual pura decorre da aproximação do artista com o samba, com a Escola Estação Primeira de Mangueira que desloca essa experiência visual da cor no espaço presente em obras como Núcleos e Relevos espaciais, para uma experimentação tátil, do movimento, do corpo, do encontro dele com outros materiais estreitando ainda mais essa relação entre corpo e obra. Essa mudança no trabalho de Oiticica, que caminha ao encontro do corpo com a obra, pode ser compreendida como uma outra camada de ambiência produzida na integração de ambos que atua na produção de humor [mood], produz um humor baseado na afinação entre o corpo e a obra.

Sobre essa experiência tátil, Pedrosa descreve a ação dos Bólides - caixa composta por diferentes materialidades, texturas e cores, que podem ser tocadas e friccionadas pelas mãos dos fruidores. Essa proposta indica uma primeira ação que aproxima corpo e obra, 
a experimentação da cor, dos materiais, não mais conduzidas apenas pela experimentação da visão. A partir dessa experiência tátil dos Bólides, as propostas artísticas de Oiticica com os Parangolés caminham para uma maior implicação do corpo na obra. Nos Bólides, o corpo é externo, o que toca a obra, ele a modifica abrindo e fechando compartimentos no ato de sua fruição, mergulhando e friccionando mão e materialidades. No $\mathrm{Pa}$ rangolé, o corpo veste essas capas, é seu esqueleto, sua estrutura. Essa inserção do corpo na obra em uma interação simbiótica indica como ele está integralmente implicado nela. Essa mudança da percepção do corpo, do sensório, da participação do fruidor nos trabalhos de Oiticica acompanha a entrada do artista na Mangueira onde ele se conecta ao samba e ao carnaval - festividades, manifestações culturais em que o corpo, seu movimento, sua relação com a fantasia/indumentária também indicam outras formas de se manifestar socialmente.

Em Anotações sobre o Parangolé (1965), Oiticica descreve essa relação entre o Parangolé e o corpo fazendo uma comparação ao estandarte, o qual deve ser carregado, vivificado por um indivíduo. Nesta mesma análise, o artista também pontua a necessidade de participação direta do corpo nas capas, que também fazem parte desse projeto-parangolé e são vivificadas no encontro entre corpo e cor no experimentar do movimento, da dança. Partindo dessa ação participativa demandada nessas obras, Hélio Oiticica define o espectador como participador. Além disso, também descreve a relação entre a ação de vestir e assistir que compõe a ambiência produzida por essas obras dada a partir da afinação entre o indivíduo que veste - o núcleo estrutural da obra, relação subjetivo vivencial - e o que assiste - conduzido ao plano espaço-temporal - compondo um ciclo vestir-assistir. (OITICICA, 1986 [1965], p. 71) A composição de uma ambiência pelo Parangolé é resumida por Oiticica:

0 Parangolé revela então o seu caráter fundamental de "estrutura ambiental", possuindo um núcleo principal: o participador-obra, que se desmembra em "participador" quando assiste e "obra quando assistida de fora nesse espaço-tempo ambiental. Esses núcleos participador-obra, ao se relacionarem num ambiente determinado (numa exposição, por ex.), criam um "sistema ambiental". (OITICICA, 1986 [1965], p. 72)

Poiésis, Niterói, v. 19, n. 32, jul./dez. 2018 
A fala de Oiticica, com as devidas diferenças de contexto, se aproxima de alguns pontos da discussão sobre Stimmung de Gumbrecht, acerca dessa dimensão climática da obra de arte, da leitura desse conceito como afinação entre obra e observador que conforma uma ambiência tal como Gumbrecht descreve sobre a pintura de Caspar David Friedrich, através do conceito de "observação de segunda ordem" de Niklas Luhman.

Ainda no texto Anotações sobre o parangolé, Oiticica define o programa ambiental e indica outras possibilidades para seu desenvolvimento para além de obras como Núcleos, Penetráveis, Bólides e Parangolés caminhando para intervenções em outros ambientes, tal como em espaços públicos, na tentativa de deslocar a arte do museu, transgredindo essa instituição e seu espaço de exposição. Como forma de ocupar esses espaços públicos, Oiticica propõe "apropriações ambientais": a apropriação de ambientes e a criação de ambientes.

\section{0 corpo em ambiência: política e afecções}

"Incorporo a revolta", essa é a frase presente no Parangolé P15, Capa $11^{5}$ de 1967, composto por camadas de tecidos de diferentes texturas, materialidades e cores que recaem sobre o corpo que o vivifica. No movimento corporal revela-se essa frase presente em uma das camadas. O verbo incorporar, conjugado em primeira pessoa, significa dar ou tomar corpo, juntar, ser inserido. Pensando o corpo no Parangolé como estrutura, "motor" da obra, é possível compreender, neste caso, que ele ao integrar a obra passa a ser um receptáculo da revolta, indicando uma leitura pública do corpo proposta por Oiticica que incorpora o gesto e os afetos/afecções como posicionamento e forma de manifestação política. Assim, nesta obra fica evidente duas percepções sobre o corpo e seu gesto: a artística - frui dessa experiência sensorial e ao mesmo tempo estrutura a obra -, e a política, na medida em que incorporar a revolta é uma ação direcionada ao corpo. Quem veste incorpora o sentido político no gesto corporal; quem assiste à incorporação entra em contato com o corpo que performatiza criando um espaço intercorporal, sendo absorvido por essa ambiência criada na sintonia entre corpo que veste e o corpo que assiste, ciclo vestir-assistir. (OITICICA, 1986 [1965], p. 71) 
Irene Small (2016) faz uma leitura dos Parangolés afirmando que essas obras têm potência de deslocar o corpo de seus significados sociais, desnaturalizando "as restrições sociais que organizam e controlam os corpos através de raça, classe e gênero" (SMALL, 2016, p. 184) que recaem sobre ele na esfera pública. A colocação de Small aponta para uma interpretação do poder dessas obras de "dissolver" as camadas de significado social dados ao corpo, que, ao despi-lo desses sentidos simbólicos, homogeneíza-o, iguala essas caraterizações estabelecendo uma impessoalidade, logo publicizando-o. Assim, essa dissolução de significados indica a compreensão de um sentido político-público do corpo que pode ser esclarecida através da imagem do estandarte que a própria autora evoca no texto. O estandarte é um objeto utilizado no Carnaval, para apresentar/representar as escolas de samba nos desfiles, e nas manifestações (cartazes e faixas). Em ambos os casos, o corpo que o carrega dá vida e o anima; nesse ato de carregar, ele é ao mesmo tempo corpo físico e público - despe-se de suas características pessoais, torna-se um abre alas, representa a escola, enquanto nas manifestações é a representação de uma causa conjunta.

Na construção dessa leitura política do Parangolé, Small traça um paralelo com a ação do manifesto artístico, um texto destinado a anunciar e afirmar a identidade de determinado grupo. Ao analisar o Parangolé Estandarte 1 (1964), a autora afirma que ele tem uma função manifesto, na medida em que assume essa forma de estandarte e, por sua vez, constrói um significado político exprimindo a identidade de um grupo social - neste caso, ele pode ser lido como um manifesto afirmando a identidade do Carnaval das escolas de samba, do samba e dos moradores da Mangueira que partilham da cultura popular socialmente marginalizada desde seu nascimento nos morros do Rio de Janeiro. Esse paralelo entre o estandarte e essa obra de Oiticica fica ainda mais nítido no texto quando Small compara essa imagem com outra, a de uma passeata em 23 de agosto de 1968 publicada no Correio da Manhã (SMALL, 2016, p. 203), em que dois indivíduos carregam uma faixa de protesto nas ruas.

Small sinaliza que essa relação de Oiticica com a Escola de Samba, estabelecida no início de 1964, abre um espaço de descoberta do corpo que se reflete em sua obra. Dinâmicas

Poiésis, Niterói, v. 19, n. 32, jul./dez. 2018. 
corporais expressas através do ritmo, da dança, do samba, do Carnaval, inspiram outras interações entre corpo-obra. Adicionado a esse contexto sociocultural, Small argumenta que essa abertura de percepção também passa pela questão da sexualidade, pela experiência do próprio corpo do artista; por isso, a autora não coloca como mera coincidência que a primeira experiência sexual do artista também tenha ocorrido no mesmo período em que o Parangolé foi concebido.

Parangolé refere-se a uma gíria que circulava nas favelas do Rio de Janeiro, mas em 1964 já era um termo obsoleto. (SMALL, 2016, p. 188) O fato dessa palavra circular nesse espaço indica que a apropriação dela traz uma carga de significado a esse "objeto", como se nele confluísse uma imagem do local social em que essa expressão circula. Ou seja, Parangolé evoca a paisagem de uma arquitetura "precária", de um lugar marginalizado e de expressões culturais como o samba, também socialmente colocados à margem.

O Parangolé é o fruto estranho, como sugere Florencia Garramuño $(2014)^{6}$, ao tratar do episódio de exibição desse trabalho na exposição Opinião $65^{7}$ (1965) no MAM-RJ em que Oiticica convida amigos e membros da Mangueira para apresentar a obra nesse espaço. Oiticica, junto aos passistas, adentra o museu como se reproduzisse nesse ambiente um carnaval: os corpos em movimento e a música acompanhavam esse desfile no interior de um museu composto como um cubo branco, destinado a expografias e a obras mais próximas de categorias tradicionais: escultura e pintura. Os parangolés geraram uma perturbação nesse ambiente, tensionando a configuração do espaço do museu e também provocando um tensionamento social já que se tratava de pessoas negras e oriundas da Mangueira que adentravam esse espaço ocupado pela elite. Essa ação foi retirada de dentro do museu, mas continuou no lado de fora.

O episódio de exibição do Parangolés indica como esses corpos em movimento não cabiam em uma configuração de um museu tradicional, que rejeitou-os, forçou-os a sair e a ocupar o espaço externo do MAM. Esse fato ocorre meses antes do Ato Institucional no 2, que extinguiu partidos políticos, permitiu a intervenção federal nos Estados, autorizou o presidente a cassar mandatos parlamentares e a suspender direitos políticos, permitiu a 
intervenção do Poder Executivo no Poder Judiciário e estabeleceu eleições indiretas para Presidência da República, indicando o endurecimento do regime militar.

Oiticica, no texto Anotações sobre o Parangolé, no trecho "Programa ambiental" (1966), manifesta-se em favor dessa ocupação do espaço público, das ruas e dos parques, defende essa posição como uma crítica ao museu, manifesta-se em favor da tomada do espaço público, o que por sua vez, nesse contexto, pode ser lido como uma posição de enfrentamento político na medida em que, no texto, ele também fomenta atitudes que transgridam a ordem nesses locais, "convocando" uma ação transgressora do corpo:

Parangolé é a antiarte por excelência, inclusive pretendo estender o sentido de "apropriação" às coisas do mundo com que deparo nas ruas, terrenos baldios, campos, o mundo do ambiente, enfim - coisas que não seriam transportáveis, mas para as quais eu chamaria o público à participação - seria isto um golpe fatal aos museus, galeria de arte etc., e ao próprio conceito de "exposição" [...] Museu é o mundo; é a experiência cotidiana: os grandes pavilhões para mostras industriais são os que ainda servem para tais manifestações: para obras que necessitem de abrigo, porque as que disso não necessitarem devem mesmo ficar nos parques, terrenos baldios da cidade [...] gostaria de colocar uma obra perdida, solta, displicentemente para ser "achada" pelos passantes, ficantes, e descuidistas, no Campo de Santana, no centro do Rio de Janeiro[...] como fazem falta os parques! - são uma espécie de alívio: servem para passa o tempo, para malandrear, para amar, para cagar etc. (OITICICA, 1986 [1966], p. 78-79) [grifo nosso]

O indivíduo que transgrede é socialmente intitulado como marginal, palavra que define o corpo que está à margem das normas e das regras sociais. Oiticica, em 1965, fez o Bólide Caixa 18 (B33) "Homenagem a Cara de Cavalo", no qual o artista homenageia seu amigo e se apropria da imagem do bandido Cara de Cavalo executado a tiros, veiculada pelo Jornal do Brasil em 1964, para compor esse bólide. A partir dessa imagem de um corpo de um transgressor, executado, Oiticica faz uma crítica a essa leitura do marginal e critica essa imagem veiculada pelo jornal com o intuito de espetacularizar essa morte e exibi-la como um troféu, promovendo um gozo social como o artista expõe no texto $O$ herói antiherói e o anti-herói anônimo (1968).

Poiésis, Niterói, v. 19, n. 32, jul./dez. 2018. 
Nesse texto, assim como nessa obra, fica evidente o pensamento de Oiticica sobre esse local social marginal. Estar à margem da arte e estar à margem da ordem culminará no trabalho Seja Marginal, seja Herói em 1968, um estandarte em que o artista manifesta por uma condição marginal. Neste sentido, usa a ambivalência da palavra marginal: estar à margem; estar fora da lei. Pensando os diversos pontos tratados ao longo deste ensaio, é possível afirmar que essa condição marginal de Oiticica é experimentada de diferentes modos no Parangolé - assume uma nova linguagem que transgride o espaço bidimensional da pintura, as tradições artísticas, a relação contemplativa entre obra e observador e o museu; além de dialogar com um espaço socialmente marginalizado, a favela - e em Seja Marginal, Seja Herói em que esse estar à margem é nitidamente pensado como uma forma de se manifestar politicamente contra o conservadorismo, os valores burgueses e a ditadura militar. Em suma, essa condição marginal é uma linha que atravessa a obra de Oiticica e pode ser conectada a análise que Flatley (2017) faz de Andy Warhol, ao observar essa condição marginal experimentada pelo artista na sociedade norte-americana. Além disso, vale ressaltar que obras como Suicide (1963) e Electric Chair (1964) também propõem, como Bólide "Homenagem a Cara de Cavalo" a discussão sobre a violência, tanto a que está em poder do Estado - que mata o corpo de um marginal seja a tiros, seja através da cadeira elétrica - quanto a que faz parte de um cotidiano social e é veiculada de forma espetacular pela mídia que produz certo gozo no espectador.

Este ensaio indica a centralidade do corpo na obra de Helio Oiticica: nos Núcleos, o corpo participa do ambiente criado, enquanto no Parangolé ele é a estrutura que compõe o mood, por sua vez a obra. O corpo em Oiticica é o receptáculo da revolta: é marginal, assume essa condição como forma do fazer político que vai se modificando ao longo da trajetória do artista; assume outros modos de transgressão, como a desterritorialização do gênero expressa no texto Discovery of Hermaphrodipotesis (1969) que indica uma ação política do corpo atravessada pela questão da sexualidade e das afecções. 


\title{
Notas
}

\begin{abstract}
${ }^{1}$ Em As noções de Stimmung em uma Série Histórica: entre disposição e atmosfera, Arlenice Almeida da Silva tece uma história do conceito, mostra sua origem no século XVIII, na teoria musical, e suas apropriações, permanências e transformações ao longo do tempo, mapeando-o em Kant, Fitche, Alöis Riegl e György Lukács. Na teoria musical, o conceito tem um sentido de proporção entre tons ou instrumentos musicais que se mantém na compreensão de Kant, na Crítica do Juízo; o conceito preserva sua condição de harmonia, o equilíbrio entre as faculdades emocionais e racionais é o pressuposto do juízo de gosto. Em Fichte, essa leitura harmônica se dissolve, dá lugar a uma desarmonia, o direcionamento do impulso estético que se estende ao infinito; a Stimmung não está na obra mas na própria forma de movimento da subjetividade do artista que se realiza com autonomia (DA SILVA, 2016, s. p.). Alöis Riegl concebe uma abordagem histórica do conceito e o desenvolve em paralelo ao seu conceito de Kunstwollen (vontade de arte). Da Silva afirma que em Riegl a leitura mais adequada de Stimmung é a de campo visual ou atmosfera (DA SILVA, 2016, s. p). Já em Lukács, a Stimmung é vertida como tonalidade da alma. Adicionado a essa leitura, Gumbrecht (2014) também faz uma análise das camadas desse conceito apresentando as mutações e permanências nas leituras de Friedrich Hölderlin, Nietzsche, Alöis Riegl e Martin Heidegger que oscilam entre harmonia, mediação, existência completa e princípio de nostalgia. (GUMBRECHT, 2014, p. 18-19)
\end{abstract}

2 Das nuances entre os conceitos de mood e climate, Gumbrecht afirma: "Mood refere-se a uma sensação interior, um estado de espírito tão privado que não pode sequer ser circunscrito com grande precisão. Climate diz respeito a alguma coisa objetiva que está em volta das pessoas e sobre elas exerce uma influência física." (GUMBRECHT, 2014, p. 12)

${ }^{3}$ Conceito formulado por Raymond Williams.

${ }^{4}$ Chama atenção nesse texto de Pedrosa a utilização de termos e expressões como "atmosfera”, "estados de afetividade”, "humor", “ ambiente" e "ambiência” usados no decorrer de sua fala para caracterizar essa leitura da arte ambiental de Oiticica.

${ }^{5}$ Essas denominações do Parangolé são constituídas por Oiticica partindo de parâmetros taxinômicos. Essa ação de catalogar suas obras como os Bólides e os Parangolés, como analisa Irene Small (2016), parte da influência do trabalho do artista no Museu Nacional (RJ) onde seu pai atuava como pesquisador no ramo da entomologia. Segundo Small, Oiticica se apropriou dessa metodologia da biologia, a taxonomia, e a aplicou no campo estético.

${ }^{6}$ Garramuño constrói uma leitura do deslocamento na literatura e nas artes visuais utilizando como fio dessa análise o conceito de "fruto estranho", oriundo de uma obra de Nuno Ramos com o mesmo nome. No capítulo "Espécie, especificidade, pertencimento", a autora tece uma leitura mais direcionada para as artes visuais pontuando a ampliação de categorias da arte como escultura e pintura - que foram estiradas ao longo dos anos 1960 70 como indica Rosalind Krauss no ensaio A escultura no campo ampliado (1979) - citado pela autora -, que destaca esse local de não pertencimento (désappartenance) das obras de arte contemporânea. Nesse ponto, ela faz uma leitura sobre o Parangolé na exibição Opinião 65 afirmando que essa ação de Oiticica tensiona os limites, categorias e espaços de exposição da arte e, ao mesmo tempo, inaugura novos rumos para a arte brasileira em 1965. Partindo dessa reflexão, a autora tece uma comparação entre essa ação e o trabalho de Nuno Ramos expos-

Poiésis, Niterói, v. 19, n. 32, jul./dez. 2018. 
to no MAM-RJ que, segundo ela, se aproximam por propor um tensionamento desses limites das categorias da arte e do local de exibição, delas fazendo, cada uma em devida proporção, uma crítica ao museu.

grupo Opinião 65 foi formado após a instituição da ditadura militar em 31 de março de 1964. Surge como uma reação ao desmantelamento dos CPCs (Centros Populares de Cultura) da UNE. O último presidente do CPC, Ferreira Gullar, forma com outros membros o coletivo de teatro Grupo Opinião como forma de resistência e de luta política para dar continuidade as propostas dos CPCs. (SMALL, 2016, p.184-185)

\section{Referências}

BOURRIAUD, Nicolas. Estética relacional. São Paulo: Martins Fontes, 2009.

DA SILVA, Arlenice Almeida. As noções de Stimmung em uma Série Histórica: entre disposição e atmosfera. Trans/Form/Ação, Marília (São Paulo), v. 39 (número especial), 2016.

FLATLEY, J. Like Andy Warhol. Chicago: University of Chicago Press, 2017.

GARRAMUÑO, Florência. Frutos estranhos: sobre a inespecificidade na estética contemporânea. Rio de Janeiro: Rocco, 2014. (e-book)

GUMBRECHT, Hans Ulrich. Atmosfera, ambiência, Stimmung: sobre um portencial oculto da literatura. Trad. Ana Isabel Soares. Rio de Janeiro: Contraponto; Editora PUC-Rio, 2014.

OITICICA, Helio. Anotações sobre o Parangolé. In OITICICA, H. Aspiro ao grande labirinto, Rio de Janeiro: Rocco, 1986.

OITICICA, Helio. A transição da cor do quadro para o espaço e o sentido de construtividade (1962) In FERREIRA, Gloria; COTRIM, Cecília (Org.). Escritos de artistas: anos 60/70. Rio de Janeiro: Jorge Zahar, 2006. 
OITICICA, Helio. O Herói anti-herói e o anti-herói anônimo (1968). Documento datilografado. Projeto Hélio Oiticica. Rio de Janeiro. Disponível em http://54.232.114.233/-extranet/enciclopedia/ho/index.cfm?fuseaction=documentos. Acesso em 30/6/2018.

PEDROSA, Mário. Arte ambiental, arte pós-moderna, Hélio Oiticica. In ARANTES, Otília (Org.). Acadêmicos e modernos: textos escolhidos III. São Paulo: Editora da Universidade de São Paulo, 2004.

SMALL, Irene. What a Body Can Do? In SMALL, Irene. Helio Oiticica, Folding the Frame. Chicago: University of Chicago Press, 2016. 